\title{
Mutations in the non-nucleoside binding-pocket interfere with the multi-nucleoside resistance phenotype
}

\author{
Kristel Van Laethem a , Myriam Witvrouwa, Christophe Pannecouque, \\ Barbara Van Remoortel ${ }^{\mathrm{a}}$, Jean-Claude Schmit ${ }^{\mathrm{b}}$, Robert Esnoufa \\ Jörg-Peter Kleim ${ }^{\mathrm{c}}$, Jan Balzarini ${ }^{\mathrm{a}}$, Jan Desmyter ${ }^{\mathrm{a}}$, Erik De Clercq ${ }^{\mathrm{a}}$ and \\ Anne-Mieke Vandamme ${ }^{\mathrm{a}}$
}

\begin{abstract}
Objectives: To investigate the genotypic and phenotypic effects of in vitro resistance selection with lamivudine and/or the second generation non-nucleoside reverse transcriptase inhibitor (NNRTI) quinoxaline HBY097 using HIV-1 isolates carrying the multi-nucleoside resistance pattern linked to the Q151M mutation.
\end{abstract}

Methods: Virus strains were selected in $\mathrm{C} 8166$ cells in the presence of increasing concentrations of lamivudine or HBY097. In parallel control experiments, the virus was cultured in $\mathrm{C} 8166$ cells in the absence of drugs. The entire reverse transcriptase encoding region was amplified using polymerase chain reaction and was subsequently sequenced. Antiviral activities of drugs were evaluated in C8166 cells.

Results: High-level resistant viruses were selected rapidly in the presence of lamivudine and quinoxaline (less than 10 passages). The multi-nucleoside resistance mutations were stable during in vitro resistance selection. Lamivudine elicited the acquisition of the M184I mutation. Phenotypic resistance to all nucleoside-analog reverse transcriptase inhibitors (NRTIs) was increased when M184I was added to the multi-nucleoside resistance background in the absence of NNRTI-resistance mutations. In most cases of HBY097 resistance selection, at least two mutations associated with NNRTI resistance resulted in high-level NNRTI resistance. The NNRTI resistancerelated mutations partially reversed the phenotypic resistance to most NRTIs, except to abacavir. The addition of the M184I mutation to the NNRTI-multi-nucleoside resistance set abolished this antagonizing effect for didanosine, zalcitabine and lamivudine, but further potentiated the phenotypic reversal for zidovudine and stavudine.

Conclusion: Changes in the non-nucleoside binding pocket must affect the conformation of residues at the dNTP binding site, and can result in a partial phenotypic reversal of the multi-nucleoside resistance phenotype. ๑ 2001 Lippincott Williams \& Wilkins

AIDS 2001, 15:553-561

Keywords: Antiretroviral therapy, HIV resistance mutations, reverse transcriptase inhibitors, multi-nucleoside resistance, phenotypic reversal

Introduction

After the failure of monotherapy, mainly due to the relatively rapid development of HIV-1 resistance to the drug, combination therapy with three or more drugs is the current standard in anti-HIV therapy [1]. The highly suppressed viral replication and the different spectrum of primary resistance mutations for the different drugs provide a good rationale to expect delayed

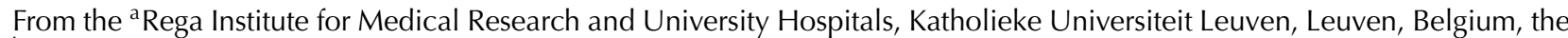
${ }^{\mathrm{b}}$ Retrovirology Laboratory, Centre Hospitalier de Luxembourg, Luxembourg and ${ }^{\mathrm{C}}$ Glaxo-Wellcome R\&D, Clinical Virology, Stevenage, UK.

Correspondence to Anne-Mieke Vandamme, Rega Institute for Medical Research, Minderbroedersstraat 10, B-3000 Leuven, Belgium.
}

Tel: +32 163321 60; fax: +32 163321 31; e-mail: vandamme@uz.kuleuven.ac.be

Received: 15 June 2000; revised: 12 September 2000; accepted: 20 December 2000. 
resistance to the drug combination [2]. However, during combination therapy complex resistance patterns may emerge. It has been reported that combinations of nucleoside reverse transcriptase (RT) inhibitors (NRTIs) can select for a set of resistance mutations (A62V, S68G, V75I, F77L, F116Y and Q151M), with Q151M as marker mutation, a set not seen under monotherapy [3-7]. This set confers cross-resistance to all currently used NRTIs, with levels of resistance to didanosine, zalcitabine and stavudine that are significantly higher than the resistance levels observed for virus mutants developed under monotherapy. The presence of other mutations in combination with this so-called multi-nucleoside resistance (MNR) set are necessary to confer high level resistance towards lamivudine and abacavir $[7,8]$.

A second MNR pattern has been described [9,10], that is marked by insertions around RT codon 69 and is also responsible for high-level resistance to multiple NRTIs. Even more significant reductions in sensitivity are observed when the 69-insertion strains carry other zidovudine-associated mutations $[9,11]$.

The non-nucleoside RT inhibitors (NNRTIs) are another class of powerful RT inhibitors. The use of 'first generation' NNRTIs in monotherapy has proved disappointing because of the extremely fast (within weeks) development of phenotypic resistance to the drugs, which requires only a single mutation in the HIV-1 RT gene [12-15]. Continuing anti-HIV drug development has led to the pre-clinical evaluation of second generation NNRTIs that are even more potent and retain activity against virus strains resistant to the first generation NNRTIs [16-19]. One of these second generation NNRTIs, the quinoxaline HBY097, generally requires multiple mutations in the HIV-1 RT for high-level resistance [20-23]. For this quinoxaline a single, but crippling, mutation at amino acid 190 in the $R T$ gene has also been observed [21]. In vitro resistance selection with HBY097 and lamivudine performed on zidovudine-resistant laboratory strains carrying variations of the 'classical' resistance mutation set (M41L and $\mathrm{T} 215 \mathrm{Y}$ ) in the $R T$ gene, resulted in HIV-1 strains that were phenotypically highly resistant to zidovudine and lamivudine, but that were still sensitive to quinoxaline [24]. The genotypic and phenotypic effects of resistance selection with quinoxaline on HIV-1 carrying the MNR set of mutations characterized by the presence of the Q151M mutation, in the $R T$ gene are not known.

We have previously described a patient isolate that had acquired the mutations A62A/V, S68G, V75I, F77L, F116Y and Q151M after sequential and combination therapy including zidovudine, zalcitabine, didanosine and stavudine [6]. The isolate displayed phenotypic resistance to zidovudine, didanosine, zalcitabine, stavu- dine, delavirdine and tivirapine and displayed partial resistance to lamivudine and several NNRTIs. Using this and prior isolates from the same patient, we investigated whether these patient isolates could acquire high-level resistance to all NRTIs, including lamivudine, and NNRTIs by performing in vitro resistance selection in the presence of lamivudine and the second generation NNRTI quinoxaline HBY097.

\section{Materials and methods}

\section{Patient isolates}

In 1989, patient $\mathrm{L}$ started antiviral treatment that changed frequently during the 6 years of follow-up, until the patient died in 1995. The sequential isolates L1 to L4 were taken at different time points during therapy, which consisted of zidovudine + interferon$\alpha /$ interferon- $\alpha$ (L1)/interferon- $\alpha+$ zalcitabine/interferon- $\alpha+$ didanosine (L2)/zidovudine + didanosine/ zalcitabine/stavudine (L4) (+ denotes combination therapy,/denotes sequential therapy) [6]. Patient-derived peripheral blood mononuclear cells were cocultured with peripheral blood mononuclear cells from seronegative blood donors and the virus supernatant was used to infect C8166 cells (obtained from the Medical Research Council, UK) to obtain high-titre virus stocks (L1, L2 and L4) as described [6].

\section{In vitro resistance selection}

The selection procedures were performed in RPMI 1640 (Life Technologies, Merelbeke, Belgium) with 20 mmol/l HEPES buffer, supplemented with 10\% heatinactivated fetal calf serum, $2 \mathrm{mmol} / \mathrm{l}$ L-glutamine, $0.1 \%$ sodium bicarbonate and $20 \mu \mathrm{g} / \mathrm{ml}$ gentamicin. C8166 cell cultures were infected with L1, L2 and L4 in the presence of increasing amounts of quinoxaline HBY097 and were passaged every 3 to 4 days. When $\pm 75 \%$ cytopathic effect was reached, culture supernatant was harvested and 1/10 of the volume was used to infect new C8166 cells, seeded at a concentration of 150000 cells $/ \mathrm{ml}$. Virus stock L4 was also cultured in C8166 cells (alone or after HBY097 resistance selection) using increasing concentrations of lamivudine. In control experiments, the virus stocks L1, L2 and L4 were cultured in C8166 cells in parallel, in the absence of lamivudine or HBY097.

\section{RNA extraction, PCR and sequencing}

RNA was extracted from culture supernatant using RNAzolB (Biotecx Laboratories, Houston, Texas, USA) or the QIAamp Viral RNA kit (Westburg, Leusden, The Netherlands). cDNA synthesis with a specific primer (RT02) was performed using MuLVRT from PE Biosystems (Foster City, California, USA). Nested polymerase chain reaction (PCR) was performed using RT01/RT02 as outer, and M13USP- 
A35/M13RSP-NE-1(35) or AV3-VD21 as inner primers. The PCR-population sequencing was done on an ABI Prism 310 or ABI Prism 377 automated sequencer (PE Biosystems) using the ABI PRISM Dye Terminator Cycle Sequencing Kit or the ABI PRISM BigDye Terminator Cycle Sequencing Ready Reaction Kit (PE Biosystems) with the primers M13USP, M13RSP, AV36 and AV44 or with AV3, AV59, AV61 and AV192, providing the sequence of the entire $\mathrm{RT}$ (polymerase and $\mathrm{RNaseH}$ domains). Conditions and primers are described elsewhere [25-28]. Further analysis of the sequences was performed using the software packages Factura 1.2.0 and Sequence Navigator 1.0.1 (PE Biosystems).

\section{Phenotypic resistance assays}

Antiviral activities of drugs were evaluated in C8166 cells. The drug inhibitory effects on virus-induced cytopathic effect was evaluated by the 3-(4,5-dimethylthiazol-2-yl)-2,5-diphenyltetrazolium bromide (MTT) method, as described elsewhere [27]. The drugs tested were zidovudine, didanosine, zalcitabine, stavudine and foscarnet (Sigma, St. Louis, Missouri, USA), lamivudine and abacavir (Glaxo-Wellcome, Stevenage, UK), quinoxaline HBY097 (Hoechst, Frankfurt, Germany), tivirapine (TIBO R86183) and loviride (a-APA R89439) (kindly provided by Dr. K. Andries, Janssen Research Foundation, Beerse, Belgium), nevirapine (BI-R G-587; Boehringer Ingelheim, Ridgefield, Connecticut, USA), emivirine (MKC-442; a HEPT-derivative; kindly provided by Dr. M. Baba, Kagoshima University, Japan), TSAO- $\mathrm{m}^{3} \mathrm{~T}$ (kindly provided by Dr. M.-J. Camarasa and Dr. M.-J. Pérez-Pérez, CSIC, Instituto de Quimica Medica, Madrid, Spain), delavirdine (BHAP U-90152; synthesized by Dr. R. Kirsh, Hoechst, Frankfurt, Germany) and UC781 (kindly provided by Uniroyal, Guelph, Ontario, Canada), adefovir and tenofovir (kindly provided by N. Bischofberger, Gilead Sciences, Foster City, California, USA).

\section{Results}

\section{Genotypic and phenotypic characteristics of cultured patient virus isolates in the absence of resistance selection}

The patient isolates L1, L2 and L4, that were used for resistance selection, were also passaged in parallel in the absence of drug resistance selection (L1S, L2S and L4S) to be able to discriminate between amino acid changes due to the culturing procedure and those due to drug resistance selection. The genotypic and phenotypic profiles of the patient isolates L1S, L2S and L4S are given in Tables 1 and 2. The amino acid sequences of the cultured variants were identical to the sequences of the original patient isolates [6] with the exception that the original L4 isolate differed from the cultured L4S

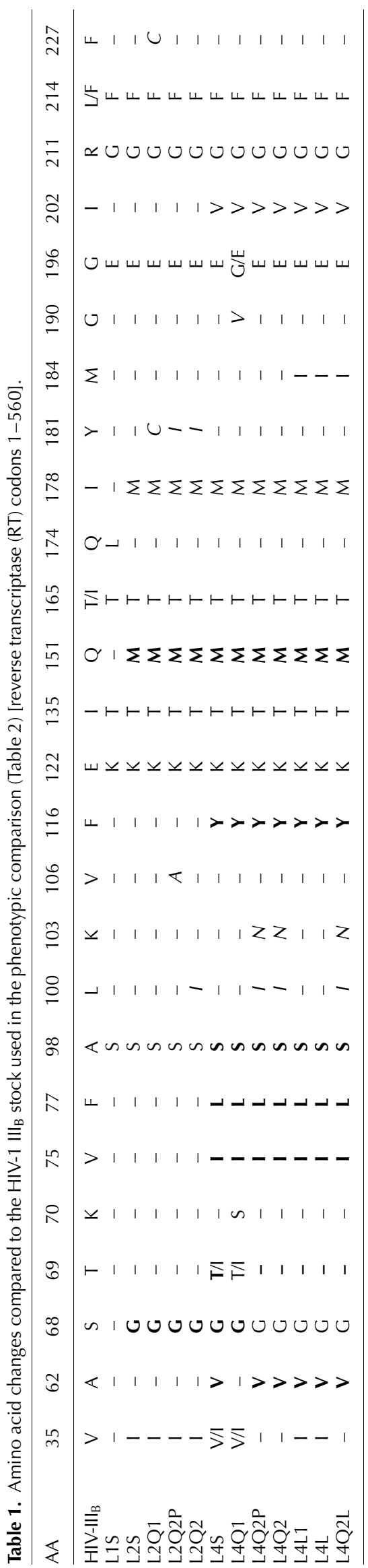


Table 1. (Continued).

\begin{tabular}{lccccccccccccccccccc}
\hline AA & 272 & 277 & 286 & 297 & 329 & 346 & 356 & 376 & 432 & 447 & 461 & 468 & 470 & 471 & 483 & 512 & 519 & 524 & 554 \\
\hline HIV-III & $\mathrm{P}$ & $\mathrm{R}$ & $\mathrm{T}$ & $\mathrm{E}$ & $\mathrm{I}$ & $\mathrm{F}$ & $\mathrm{R}$ & $\mathrm{T}$ & $\mathrm{E}$ & $\mathrm{N} / \mathrm{S}$ & $\mathrm{R} / \mathrm{K}$ & $\mathrm{T} / \mathrm{P}$ & $\mathrm{T}$ & $\mathrm{D} / \mathrm{N}$ & $\mathrm{Y}$ & $\mathrm{Q}$ & $\mathrm{N}$ & $\mathrm{Q}$ & $\mathrm{A}$ \\
L1S & $\mathrm{A}$ & - & $\mathrm{A}$ & $\mathrm{K}$ & $\mathrm{L}$ & - & - & $\mathrm{A}$ & $\mathrm{E} / \mathrm{D}$ & $\mathrm{N}$ & $\mathrm{R}$ & $\mathrm{S}$ & $\mathrm{T} / \mathrm{A}$ & $\mathrm{D}$ & $\mathrm{H}$ & $\mathrm{K}$ & $\mathrm{S}$ & $\mathrm{Q} / \mathrm{H}$ & $\mathrm{T}$ \\
L2S & $\mathrm{A}$ & - & $\mathrm{A}$ & $\mathrm{K}$ & $\mathrm{L}$ & - & - & $\mathrm{A}$ & $\mathrm{D}$ & $\mathrm{N}$ & $\mathrm{R}$ & $\mathrm{S}$ & - & $\mathrm{D}$ & $\mathrm{H}$ & $\mathrm{K}$ & $\mathrm{S}$ & - & $\mathrm{T}$ \\
L2Q1 & nd & nd & nd & nd & nd & nd & nd & nd & nd & nd & nd & nd & nd & nd & nd & nd & nd & nd & nd \\
L2Q2P & nd & nd & nd & nd & nd & nd & nd & nd & nd & nd & nd & nd & nd & nd & nd & nd & nd & nd & nd \\
L2Q2 & $\mathrm{A}$ & - & $\mathrm{A}$ & $\mathrm{K}$ & $\mathrm{L}$ & - & - & $\mathrm{A}$ & $\mathrm{D}$ & $\mathrm{N}$ & $\mathrm{R}$ & $\mathrm{S}$ & - & $\mathrm{D}$ & $\mathrm{H}$ & $\mathrm{K}$ & $\mathrm{S}$ & - & $\mathrm{T}$ \\
L4S & $\mathrm{A}$ & $\mathrm{R} / \mathrm{K}$ & $\mathrm{A}$ & $\mathrm{K}$ & $\mathrm{L}$ & - & - & $\mathrm{A}$ & $\mathrm{D}$ & $\mathrm{N}$ & $\mathrm{R}$ & $\mathrm{S}$ & - & $\mathrm{D}$ & $\mathrm{H}$ & $\mathrm{K}$ & $\mathrm{S}$ & - & $\mathrm{T}$ \\
L4Q1 & nd & nd & nd & nd & nd & nd & nd & nd & nd & nd & nd & nd & nd & nd & nd & nd & nd & nd & nd \\
L4Q2P & nd & nd & nd & nd & nd & nd & nd & nd & nd & nd & nd & nd & nd & nd & nd & nd & nd & nd & nd \\
L4Q2 & A & - & $\mathrm{A}$ & $\mathrm{K}$ & $\mathrm{L}$ & - & - & $\mathrm{A}$ & $\mathrm{D}$ & $\mathrm{N}$ & $\mathrm{R}$ & $\mathrm{S}$ & - & $\mathrm{D}$ & $\mathrm{H}$ & $\mathrm{K}$ & $\mathrm{S}$ & - & $\mathrm{T}$ \\
L4L1 & nd & nd & nd & nd & nd & nd & nd & nd & nd & nd & nd & nd & nd & nd & nd & nd & nd & nd & nd \\
L4L & $\mathrm{A}$ & - & $\mathrm{A}$ & $\mathrm{K}$ & $\mathrm{I} / \mathrm{L}$ & $\mathrm{F} / \mathrm{L}$ & $\mathrm{R} / \mathrm{T}$ & $\mathrm{A}$ & $\mathrm{D}$ & $\mathrm{N}$ & $\mathrm{R}$ & $\mathrm{S}$ & - & $\mathrm{D}$ & $\mathrm{H}$ & $\mathrm{K}$ & $\mathrm{S}$ & - & $\mathrm{T}$ \\
L4Q2L & $\mathrm{A}$ & - & $\mathrm{A}$ & $\mathrm{K}$ & $\mathrm{L}$ & - & - & $\mathrm{A}$ & $\mathrm{D}$ & $\mathrm{N}$ & $\mathrm{R}$ & $\mathrm{S}$ & - & $\mathrm{D}$ & $\mathrm{H}$ & $\mathrm{K}$ & $\mathrm{S}$ & - & $\mathrm{T}$ \\
\hline
\end{tabular}

For the code of the isolates, see Figure 1. AA, amino acid; -, no difference compared to HIV-1 III $\mathrm{B}$; nd, not determined; $\mathrm{P}$, intermediate isolate; S, isolate cultured without the selective pressure of any drugs; Q1 and Q2, isolates cultured with the increasing selective pressure of HBY097 (experiments 1 and 2); L, isolate cultured with the increasing selective pressure of lamivudine; L1, isolate cultured with the stable selective pressure of $4.4 \mu \mathrm{M}$ lamivudine. MNR mutations are shown in bold type; NNRTI mutations are shown in italic type.

isolate at the following positions $\mathrm{V} 35, \mathrm{~A} 62 \mathrm{~A} / \mathrm{V}, \mathrm{T} 69$ (L4) compared to V35V/I, A62V, T69T/I (L4S). The phenotype of the isolates also remained virtually unchanged after culturing. L1S has wild-type (WT) genotype (Table 1) and phenotype (Table 2). L2S has several new mutations compared to isolate L1S, including two mutations known to be associated with multinucleoside resistance (S68G and Q151M). This results in resistance towards stavudine (14-fold), partial resistance to zidovudine (five-fold), zalcitabine (five-fold) and didanosine (seven-fold), and some increase in the $50 \%$ effective concentration $\left(\mathrm{EC}_{50}\right)$ towards NNRTIs (three- to 13-fold). L4S displayed the full pattern of mutations associated with multi-nucleoside resistance (A62V, S68G, V75I, F77L, F116Y and Q151M) (Table 1) and was highly resistant to zidovudine, didanosine, zalcitabine, stavudine and tenofovir (13- to more than 4000-fold) and partially resistant to lamivudine (fourfold) (Table 2). There was also some further increase in $\mathrm{EC}_{50}$ towards the NNRTIs tested (seven- to 23-fold) resulting in 23- and 20-fold reduced sensitivity only towards loviride and tivirapine respectively, which could be resistance in the absence of any mutations known to be linked to NNRTI resistance.

\section{Resistance selection against lamivudine and HBY097 using the isolates of patient $L$}

To estimate the impact of the M184V/I mutation on the phenotype, isolate L4 was cultured in the presence of fixed or increasing concentrations of lamivudine (L4L1 and L4L, respectively). The original virus stocks L2 and L4 were also cultured in two separate experiments in the presence of increasing concentrations of HBY097 (codes L2Q1, L2Q2, L4Q1 and L4Q2). Virus stock L4Q2 was further cultured in the presence of increasing concentrations of lamivudine (L4Q2L), in an attempt to monitor the impact of non-nucleoside resistance mutations on lamivudine resistance selection. Genotypic and phenotypic changes were evaluated with respect to HIV-1 $\mathrm{III}_{\mathrm{B}}$ and with respect to the patient isolates L1S, L2S and L4S. In all cases, highlevel resistance selection with HBY097 or lamivudine was very rapid (less than 10 passages). The details of the selection procedure are given in Figures 1 and 2.

\section{Genotypic changes after resistance selection}

From Table 1 it is obvious that the MNR mutations are very stable. They persisted during culturing of the isolates with or without selective drug pressure. All L4derived isolates (L4S, L4Q1, L4Q2, L4L1, L4L, L4Q2L) retained the mutations S68G, V75I, F77L, $\mathrm{F} 116 \mathrm{Y}$ and $\mathrm{Q} 151 \mathrm{M}$. The isolates derived from L4 (except L4Q1) acquired the A62V mutation even in the absence of drug selective pressure, suggesting its role in increasing virus fitness. In L4, this mutation was originally present as a mixed wild-type (WT)/mutant (MT) genotype (A62A/V) [6].

Using isolate L4, which was naive and WT for lamivudine, fixed or increasing concentrations of lamivudine resulted in the selection of M184I instead of M184V (L4L1, L4L and L4Q2L).

Various mutations accompanied the HBY097 resistance selection (Table 1). In almost all cases, at least two NNRTI mutations accumulated during high-level resistance selection to HBY097: Y181C + F227C for L2Q1; V106A + Y181I for L2Q2P; L100I + Y181I for L2Q2; L100I + K103N for L4Q2P, L4Q2 and L4Q2L. However, in one isolate (L4Q1), the single mutation G190V appeared after resistance selection with HBY097.

The mutations observed for codon 70 were also of particular interest. The classical zidovudine resistance mutation at this codon is K70R; but here we observed K70S which was acquired in one of the HBY097 resistance selection experiments (L4Q1). This mutation 
Table 2. Phenotypic sensitivity [50\% effective concentration $\left(\mathrm{EC}_{50}\right)$ in $\left.\mu \mathrm{M}\right]$ of the strains described in Table 1.

\begin{tabular}{|c|c|c|c|c|c|c|c|c|}
\hline Drug & $\mathrm{III}_{\mathrm{B}}$ & L1S & L2S & L2Q2 & L4S & L4L & L4Q2 & L4Q2L \\
\hline Zidovudine & $0.0090 \pm 0.0105$ & $\begin{array}{c}0.014 \pm 0.005 \\
(1.6)\end{array}$ & $\begin{array}{c}0.043 \pm 0.013 \\
(4.8)\end{array}$ & $\begin{array}{c}0.035 \pm 0.021 \\
(3.9)\end{array}$ & $\begin{array}{l}40 \pm 37 \\
(4444)\end{array}$ & $\begin{array}{c}>210 \\
(>23333)\end{array}$ & $\begin{array}{c}0.71 \pm 0.29 \\
(79)\end{array}$ & $\begin{array}{c}0.30 \pm 0.16 \\
(33)\end{array}$ \\
\hline Zalcitabine & $0.29 \pm 0.17$ & $\begin{array}{c}0.18 \pm 0.01 \\
(0.62)\end{array}$ & $\begin{array}{c}1.5 \pm 0.1 \\
(5.2)\end{array}$ & $\begin{array}{c}0.83 \pm 0.10 \\
(2.9)\end{array}$ & $\begin{array}{l}6.6 \pm 1.4 \\
(23)\end{array}$ & $\begin{array}{r}32 \pm 23 \\
(110)\end{array}$ & $\begin{array}{c}1.6 \pm 0.6 \\
(5.5)\end{array}$ & $\begin{array}{l}>118 \\
(>407)\end{array}$ \\
\hline Didanosine & $4.8 \pm 0.7$ & $\begin{array}{c}3.7 \pm 0.4 \\
(0.77)\end{array}$ & $\begin{array}{r}33 \pm 7 \\
(6.9)\end{array}$ & $\begin{array}{c}12 \pm 0 \\
(2.6)\end{array}$ & $\begin{array}{c}213 \pm 58 \\
(44)\end{array}$ & $\begin{array}{l}>530 \\
(>111)\end{array}$ & $\begin{array}{c}158 \pm 77 \\
(33)\end{array}$ & $\begin{array}{l}>466 \\
(>97)\end{array}$ \\
\hline Stavudine & $0.074 \pm 0.028$ & $\begin{array}{c}0.12 \pm 0.03 \\
(1.6)\end{array}$ & $\begin{array}{l}1.0 \pm 0.2 \\
(14)\end{array}$ & $\begin{array}{c}0.41 \pm 0.12 \\
(5.5)\end{array}$ & $\begin{array}{l}20 \pm 17 \\
(270)\end{array}$ & $\begin{array}{r}19 \pm 15 \\
(257)\end{array}$ & $\begin{array}{c}1.9 \pm 0.9 \\
(26)\end{array}$ & $\begin{array}{c}0.49 \pm 0.13 \\
(6.6)\end{array}$ \\
\hline Lamivudine & $0.83 \pm 0.68$ & $\begin{array}{c}0.25 \pm 0.16 \\
(0.30)\end{array}$ & $\begin{array}{c}0.39 \pm 0.13 \\
(0.47)\end{array}$ & $\begin{array}{c}0.16 \pm 0.01 \\
\quad(0.19)\end{array}$ & $\begin{array}{c}3.5 \pm 0.2 \\
(4.2)\end{array}$ & $\begin{array}{l}>546 \\
(>658)\end{array}$ & $\begin{array}{c}0.39 \pm 0.19 \\
(0.47)\end{array}$ & $\begin{array}{l}>546 \\
(>658)\end{array}$ \\
\hline Abacavir & $2.6 \pm 0.7$ & $\begin{array}{c}1.0 \pm 0.3 \\
(0.38)\end{array}$ & $\begin{array}{c}2.3 \pm 0.3 \\
(0.88)\end{array}$ & $\begin{array}{c}6.8 \pm 0.6 \\
(2.6)\end{array}$ & $\begin{array}{c}9.9 \pm 0.4 \\
(3.8)\end{array}$ & $\begin{array}{c}56 \pm 5 \\
(22)\end{array}$ & $\begin{array}{c}11 \pm 1 \\
(4.2)\end{array}$ & $\begin{array}{r}24 \pm 11 \\
(9.2)\end{array}$ \\
\hline Adefovir & $9.8 \pm 2.8$ & $\begin{array}{c}12 \pm 4 \\
(1.2)\end{array}$ & $\begin{array}{l}5.6 \pm 1.0 \\
\quad(0.57)\end{array}$ & $\begin{array}{l}2.5 \pm 0.2 \\
\quad(0.26)\end{array}$ & $\begin{array}{r}19 \pm 11 \\
(1.9)\end{array}$ & $\begin{array}{r}18 \pm 1 \\
(1.8)\end{array}$ & $\begin{array}{l}9.0 \pm 0.1 \\
(0.92)\end{array}$ & $\begin{array}{l}4.7 \pm 1.7 \\
(0.48)\end{array}$ \\
\hline Tenofovir & $4.2 \pm 1.6$ & $\begin{array}{c}2.9 \pm 0.2 \\
(0.69)\end{array}$ & $\begin{array}{c}4.9 \pm 0.5 \\
(1.2)\end{array}$ & $\begin{array}{c}3.4 \pm 0.6 \\
(0.81)\end{array}$ & $\begin{array}{l}54 \pm 20 \\
(13)\end{array}$ & $\begin{array}{c}31 \pm 18 \\
(7.4)\end{array}$ & $\begin{array}{l}9.0 \pm 0.4 \\
(2.1)\end{array}$ & $\begin{array}{l}6.2 \pm 6.1 \\
(1.5)\end{array}$ \\
\hline Foscarnet & $48 \pm 7$ & $\begin{array}{c}53 \pm 9 \\
(1.1)\end{array}$ & $\begin{array}{c}123 \pm 27 \\
(2.6)\end{array}$ & $\begin{array}{c}218 \pm 14 \\
(4.5)\end{array}$ & $\begin{array}{c}91 \pm 40 \\
(1.9)\end{array}$ & $\begin{array}{c}297 \pm 35 \\
(6.2)\end{array}$ & $\begin{array}{r}43 \pm 1 \\
(0.90)\end{array}$ & $\begin{array}{c}81 \pm 55 \\
(1.7)\end{array}$ \\
\hline Nevirapine & $0.027 \pm 0.013$ & $\begin{array}{c}0.073 \pm 0.013 \\
(2.7)\end{array}$ & $\begin{array}{c}0.17 \pm 0.01 \\
(6.3)\end{array}$ & $\begin{array}{r}>7.5 \\
(>278)\end{array}$ & $\begin{array}{c}0.48 \pm 0.17 \\
(18)\end{array}$ & $\begin{array}{c}0.21 \pm 0.05 \\
(7.8)\end{array}$ & $\begin{array}{r}>7.5 \\
(>278)\end{array}$ & $\begin{array}{r}12 \pm 0 \\
(456)\end{array}$ \\
\hline Delavirdine & $0.049 \pm 0.024$ & $\begin{array}{c}0.047 \pm 0.010 \\
(0.96)\end{array}$ & $\begin{array}{c}0.18 \pm 0.14 \\
(3.7)\end{array}$ & $\begin{array}{r}>5.7 \\
(>117)\end{array}$ & $\begin{array}{l}0.55 \pm 0.10 \\
\quad(11)\end{array}$ & $\begin{array}{c}0.37 \pm 0.24 \\
(7.6)\end{array}$ & $\begin{array}{r}>5.7 \\
(>117)\end{array}$ & $\begin{array}{c}>5.7 \\
(>117)\end{array}$ \\
\hline Loviride & $0.0064 \pm 0.0029$ & $\begin{array}{c}0.014 \pm 0.001 \\
(2.2)\end{array}$ & $\begin{array}{l}0.081 \pm 0.002 \\
\quad(13)\end{array}$ & $\begin{array}{r}>5.7 \\
(>891)\end{array}$ & $\begin{array}{c}0.15 \pm 0.04 \\
\quad(23)\end{array}$ & $\begin{array}{l}0.088 \pm 0.016 \\
\quad(14)\end{array}$ & $\begin{array}{r}>5.7 \\
(>891)\end{array}$ & $\begin{array}{l}2.5 \pm 1.2 \\
\quad(390)\end{array}$ \\
\hline Tivirapine & $0.0042 \pm 0.0015$ & $\begin{array}{c}0.0064 \pm 0.0020 \\
(1.5)\end{array}$ & $\begin{array}{c}0.030 \pm 0.010 \\
(7.2)\end{array}$ & $\begin{array}{r}>6.2 \\
(>1481)\end{array}$ & $\begin{array}{c}0.084 \pm 0.022 \\
(20)\end{array}$ & $\begin{array}{c}0.036 \pm 0.020 \\
(8.5)\end{array}$ & $\begin{array}{r}>6.2 \\
(>1481)\end{array}$ & $\begin{array}{l}4.8 \pm 0.2 \\
(1148)\end{array}$ \\
\hline Emivirine & $0.0051 \pm 0.0012$ & $\begin{array}{c}0.0063 \pm 0.0005 \\
(1.2)\end{array}$ & $\begin{array}{c}0.029 \pm 0.005 \\
(5.7)\end{array}$ & $\begin{array}{r}>6.6 \\
(>1290)\end{array}$ & $\begin{array}{c}0.096 \pm 0.009 \\
(19)\end{array}$ & $\begin{array}{c}0.044 \pm 0.026 \\
(8.7)\end{array}$ & $\begin{array}{r}>6.6 \\
(>1290)\end{array}$ & $\begin{array}{l}>6.6 \\
(>1290)\end{array}$ \\
\hline TSAO-m ${ }^{3} \mathrm{~T}$ & $0.036 \pm 0.019$ & $\begin{array}{c}0.057 \pm 0.032 \\
(1.6)\end{array}$ & $\begin{array}{c}0.10 \pm 0.01 \\
(2.7)\end{array}$ & $\begin{array}{l}>3.3 \\
(>91)\end{array}$ & $\begin{array}{c}0.32 \pm 0.01 \\
(8.9)\end{array}$ & $\begin{array}{c}0.31 \pm 0.08 \\
(8.4)\end{array}$ & $\begin{array}{l}>3.3 \\
(>91)\end{array}$ & $\begin{array}{l}>3.3 \\
(>91)\end{array}$ \\
\hline HBY097 & $0.00084 \pm 0.00010$ & $\begin{array}{c}0.00096 \pm 0.00015 \\
(1.1)\end{array}$ & $\begin{array}{c}0.0041 \pm 0.0008 \\
(4.9)\end{array}$ & $\begin{array}{r}>5.9 \\
(>7018)\end{array}$ & $\begin{array}{c}0.011 \pm 0.005 \\
(14)\end{array}$ & $\begin{array}{c}0.0059 \pm 0.0025 \\
(7.0)\end{array}$ & $\begin{array}{r}>5.9 \\
(>7018)\end{array}$ & $\begin{array}{l}3.1 \pm 0.2 \\
(3690)\end{array}$ \\
\hline UC781 & $0.0027 \pm 0.0008$ & $\begin{array}{c}0.0049 \pm 0.0011 \\
(1.8)\end{array}$ & $\begin{array}{c}0.015 \pm 0.003 \\
(5.7)\end{array}$ & $\begin{array}{r}>6.0 \\
(>2174)\end{array}$ & $\begin{array}{c}0.017 \pm 0.001 \\
(6.4)\end{array}$ & $\begin{array}{c}0.020 \pm 0.004 \\
(7.6)\end{array}$ & $\begin{array}{r}>6.0 \\
(>2174)\end{array}$ & $\begin{aligned} &>6.0 \\
&(>2174)\end{aligned}$ \\
\hline
\end{tabular}

The results are the average \pm SD of two to eight experiments performed in triplicate. Fold resistance between brackets, sensitive values in normal type $(<$ four-fold resistance), high-level resistance in bold type ( $>$ seven-fold resistance towards abacavir, didanosine, stavudine, zalcitabine, adefovir, tenofovir and foscarnet; $>15$-fold resistance towards zidovudine; $>20$-fold resistance towards

lamivudine and NNRTIs) and intermediate values (between sensitive and high-level resistance) in italic type [2]. 


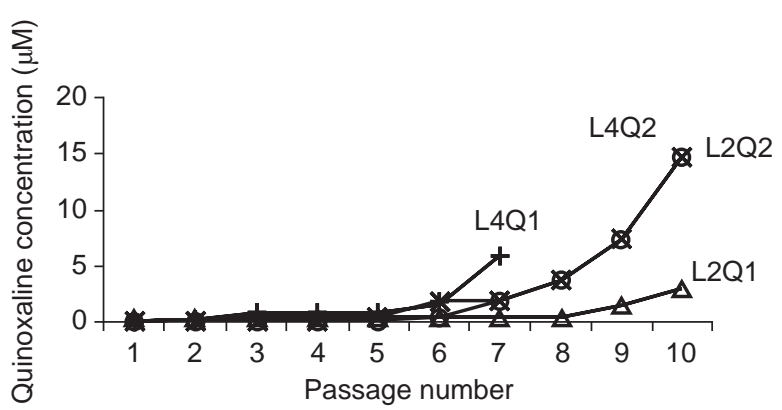

Fig. 1. Kinetics of resistance development for the HIV isolates L2 and L4 following selective pressure with quinoxaline HBY097. Selective pressure with quinoxaline HBY097 was increased upon passaging virus isolate L2 (experiment 1: $\Delta$, resulting in L2Q1 after 10 passages; and experiment 2: O, resulting in L2Q2 after 10 passages) and virus isolate L4 (experiment 1: + , resulting in L4Q1 after 7 passages and experiment 2: $\times$; resulting in L4Q2 after 10 passages) in C8166 cells as described in the methods section.

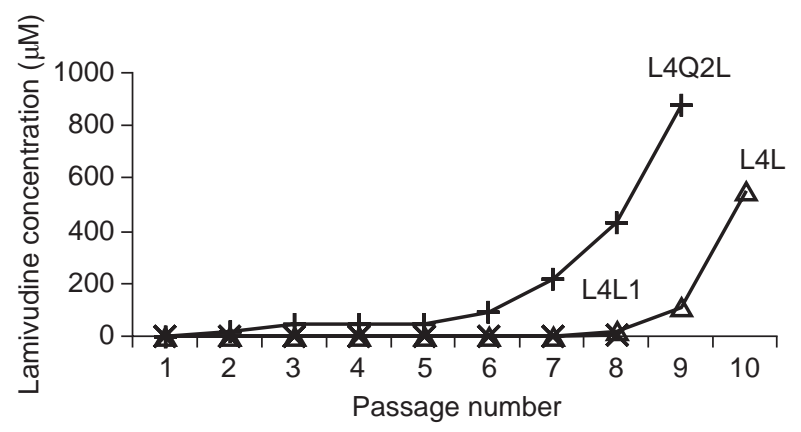

Fig. 2. Kinetics of resistance development for the HIV isolates L4 and L4Q2 following selective pressure with lamivudine. Selective pressure with lamivudine was increased upon passaging virus isolate L4 (fixed lamivudine concentration: $\times$, resulting in L4L1 after 8 passages; and increasing lamivudine concentration: $\Delta$, resulting in $\mathrm{L} 4 \mathrm{~L}$ after 10 passages) and virus isolate L4Q2 (+, resulting in L4Q2 L after 9 passages) in C8166 cells as described in the methods section.

was also observed in a later isolate of this patient, isolate L6 after a combination therapy of loviride and lamivudine [6]. T69T/I was found in L4S and L4Q1 and differs from the classical zalcitabine-resistance mutation T69D.

The polymorphic amino acid substitutions, such as E122K, I135T, I178M, G196E, I202V, R211G (not reported before) and $\mathrm{L} 214 \mathrm{~F}$, were present before culturing and were stable during culturing. The substitution V35I appeared during culturing of L4 with or without drug selection. The substitution A98S was also stable during culturing. Those isolates for which the phenotype was determined were also sequenced in the second part of RT (the region coding for amino acids 259 to 560), but showed only polymorphic amino acid substitutions in this part.

\section{Phenotype of the selected isolates}

Phenotypic resistance to all NRTIs and to foscarnet increased when the M184I mutation was added to the MNR background (L4L), whereas sensitivity towards the NNRTIs increased slightly (compared to L4S) although this may not be significant.

Upon addition of NNRTI resistance-related mutations to the background of the MNR mutations (L2Q2, L4Q2 and L4Q2L), high-level resistance to all NNRTIs was observed ( $>90$-fold). In addition, for L2Q2 and L4Q2 a partial phenotypic resistance reversal was observed for all NRTIs, except for abacavir, compared to L2S and L4S, respectively. This reversal ranged from a marginal change for zidovudine (comparing L2Q2 with L2S) to a 56-fold to zidovudine (comparing L4Q2 with L4S). The addition of the M184I mutation to the NNRTI-MNR set of mutations (L4Q2L compared to L4Q2) abolished the phenotypic resistance reversal effect for zalcitabine, didanosine and lamivudine, resulting in high-level resistance to these drugs. On the other hand, this addition of the M184I mutant to the MNR-NNRTI background further decreased the resistance for zidovudine and stavudine.

\section{Discussion}

Multidrug resistance is an emerging problem in the treatment of HIV-infected patients. The first MNR pattern reported was associated with the marker mutation Q151M, together with the other mutations A62V, S68G, V75I, F77L and F116Y of the HIV-1 RT gene [3-7]. These mutations confer high-level resistance to the NRTIs didanosine, stavudine, zalcitabine and zidovudine and intermediate-level resistance towards abacavir and lamivudine $[7,8]$. As these patients fail to respond to the nucleoside analogs that are part of the presently used combination regimens [7], it is important to have at hand RT inhibitors that are still sufficiently active against MNR strains. NNRTIs, another class of RT inhibitors, could theoretically be considered as good candidates to inhibit the replication of MNR strains. Previously, we described a patient isolate that had easily acquired the K103N mutation in a background of MNR mutations [6]. However, the NNRTI resistance was developed under a suboptimal treatment regimen with loviride monotherapy followed by loviride and lamivudine bitherapy. A well-designed combination therapy including NNRTIs and protease inhibitors should, theoretically, be able to suppress replication of MNR viruses. It is known that the K103N mutation confers cross-resistance to several NNRTIs but not to TSAO, quinoxaline S-2720 or the thiocarboxanilide UC781 [17,20]. Therefore, it would be interesting to investigate whether MNR strains can 
acquire high-level resistance to the second-generation NNRTI quinoxaline HBY097 and what are the genotypic and phenotypic effects of resistance selection with this drug.

Isolate L1S was sensitive towards all the NNRTIs tested. However, with increasing numbers of MNR related mutations (L2S and L4S), the sensitivity towards NNRTIs decreased, without ever reaching high-level resistance to these drugs. Apart from MNR mutations, other amino acid changes compared to L1S were only at positions 35 (V35I for L2S and V35V/I for L4S), 69 (T69T/I for L4S), 202 (I202V for L4S), 277 (R277R/ $\mathrm{K}$ for L4S) and 432 (E432D for L2S and L4S) which are not known to be linked to NNRTI resistance. Mutations of the MNR pattern thus seem to influence slightly the NNRTI-binding pocket.

When performing the selection with lamivudine using the virus stocks L4 and the selected HBY097-resistant L4Q2, isolates L4L1, L4L and L4Q2L developed the M184I mutation instead of the more common M184V mutation. This might be due to the relative ease of the $\mathrm{G} \longrightarrow \mathrm{A}$ mutation compared to the $\mathrm{A} \longrightarrow \mathrm{G}$ transition in HIV-1 [29] (ATG coding for amino acid M, GTA or GTG coding for amino acid V and ATA coding for amino acid I). The addition of the M184I mutation to the MNR background set increased resistance to all NRTIs.

When using isolates L2 and L4, various mutations accompanied the rapid selection for HBY097 resistance. In almost all cases, at least two mutations relating to NNRTI resistance were accumulated resulting in high-level resistance to all NNRTIs. The L100I mutation, in combination with a variable second NNRTI mutation was the most frequent outcome. In many reported HIV-1 RT/NNRTI complexes, the bound inhibitor assumes a butterfly-like shape, however HBY097 is one of the exceptions [30]. The centre of HBY097 cannot bend to form the butterfly shape, resulting in unusually extensive contacts between L100 and the inhibitor. Other observed mutations were K103N, V106A, Y181C, Y181I, G190V and F227C. Although G190E is frequently selected in vitro under HBY097 selection and G190A under nevirapine selection in vitro and in patients, this is the first report of the G190V mutation. In vitro mutagenesis experiments on the HIV-1 RT enzyme have shown that the G190V mutation is highly resistant towards quinoxaline S2720, TIBO R82150 and nevirapine, sensitive to BHAP L697661 and even hypersensitive to delavirdine (BHAP U-90152T) [21]. Although the RNA-dependent DNA polymerase activity of G190V RT retains only $39 \%$ of wild type, it is still ten times more active than the crippled G190E mutant [21]. After continued exposure to HBY097, NRTI mutations L74V/I and V75L/I can emerge in the G190E mutant, presumably due to an enhanced polymerase activity of the double mutants compared to that of the single mutant [31,32]. The isolate that developed the G190V mutation during the selection procedure (L4Q1), already carried the V75I mutant as part of the multi-nucleoside resistance pattern and this might have contributed to the emergence of the G190V mutation. A leucine substitution at RT codon 227 has already been reported for UC781 and HBY097 resistance [33], but this is the first report of the F227C mutation.

Surprisingly, upon acquisition of NNRTI resistancerelated mutations in the background of the MNR set a partial phenotypic resistance reversal for NRTIs, except for abacavir, was observed. The addition of the M184I mutation to the NNRTI-MNR set of mutations abolished this effect for zalcitabine, didanosine and lamivudine, but increased the phenotypic reversal for zidovudine and stavudine.

The X-ray structures of the RT show Q151 near the catalytic triad (D110, D185 and D186). The structure of a trapped catalytic complex [34] shows Q151 near the $2^{\prime}$ and $3^{\prime}$ positions of the ribosyl ring of the incoming nucleotide. Suboptimal interactions with the ribose analogs of NRTIs may help explain the role of the Q151M mutation in the MNR phenotype.

The mutation M184I that develops under lamivudine selective pressure, may produce steric hindrance between lamivudine and the mutant amino acid, resulting in a reduced affinity to the inhibitor. M184 also has close interactions with the sugar moiety of the terminal primer nucleotide [34] and, thus, the M184I mutation may cause some subtle changes in the geometry of the polymerization complex. Other amino acids that help define the polymerization complex include 74,110 , 115, 116, 151 and 185. Thus, the change at position 184 may increase resistance not only to lamivudine but to all NRTIs after the development of the M184I mutation in the MNR background.

Mutations in the non-nucleoside binding pocket will have an effect in the position and mobility of the catalytic triad. This would, in turn, alter the position and conformation of the incoming nucleotide and/or the template-primer. These changes may therefore account for the (partial) reversal of the MNR phenotype. How the M184I mutation appears to be able to attenuate this reversal for zalcitabine, didanosine and lamivudine, but reinforces it for zidovudine and stavudine is unclear.

We can only speculate about the possible clinical significance of this partial reversal of the MNR phenotype. Although pronounced phenotypic changes for zidovudine and stavudine have been observed, the MNR isolate was still highly resistant to these com- 
pounds after acquisition of the NNRTI mutations and showed still high-level resistance towards zidovudine and intermediate resistance towards stavudine upon addition of the M184I mutation. Additionally, it is possible that alternative or multiple mutations emerge in vivo without showing the resensitization profile as observed in vitro. This has already been observed for other zidovudine resensitization mutations, such as L74V, Y181C and M184V [13,35-37]. L74V can suppress zidovudine resistance in vitro arising from a mutation at codon 215, although not when multiple zidovudine resistance-related mutations are present [36]. However in vivo, L74V is seldom observed during a zidovudine and didanosine combination therapy and other more complex patterns might occur [3]. Like $\mathrm{L} 74 \mathrm{~V}, \mathrm{Y} 181 \mathrm{C}$ can lead to zidovudine resensitization in vitro. Although this mutation is the most common mutation with monotherapy, it seldom occurs in concomitant therapy with thymidine analogues and nevirapine, but resulted in the selection of alternative mutations $[13,38]$. M184V is another zidovudine resensitization mutation, but co-resistant viruses towards zidovudine and lamivudine have been observed after the acquisition of additional or alternative mutations $[39,40]$. However, the M184V mutation is the only mutation that has also shown to delay zidovudine resistance and restore susceptibility to zidovudine in vivo, resulting in a clinical benefit, although only transiently [41,42]. It is therefore not impossible that the NNRTI mutations reported here, may have a limited clinical benefit.

In conclusion, high-level resistant viruses were rapidly selected in the presence of lamivudine and quinoxaline. The MNR mutations were stable during in vitro resistance selection. Lamivudine elicited the acquisition of the M184I mutation. Phenotypic resistance to all NRTIs was increased when the M184I was added to the MNR background in the absence of NNRTI resistance mutations. In almost all cases of quinoxaline resistance selection, at least two mutations related to NNRTI resistance accompanied the high-level NNRTI resistance selection. The NNRTI resistancerelated mutations partially reversed the phenotype resistance to some NRTIs. The addition of the M184I mutation to the NNRTI-MNR set of mutations abolished this antagonizing effect for zalcitabine, didanosine and lamivudine, but further potentiated the phenotypic resistance reversal for zidovudine and stavudine.

\section{Acknowledgements}

The authors thank Kristien Erven for excellent technical assistance and Dr. B. A. Larder for providing the pHIV $\Delta$ RT plasmid.
Sponsorship: This work was partially supported by the Biomedical Research Programme of the European Commission (EC BIOMED2 grant BMH4-CT-95-1634), the Flemish Fonds voor Wetenschappelijk Onderzoek (FWO grant G.0104.98) and the Geconcerteerde Onderzoeksacties (GOA 95/5, GOA 00/12) of the Flemish Community.

\section{References}

1. Vandamme A-M, Van Vaerenbergh K, De Clercq E. Anti-human immunodeficiency virus drug combination strategies. Antiviral Chem Chemother 1998, 9:187-203.

2. Vandamme A-M, Van Laethem K, De Clercq E. Managing resistance to anti-HIV drugs. Drugs 1999, 57:337-361.

3. Shafer RW, Kozal MJ, Winters MA, et al. Combination therapy with zidovudine and didanosine selects for drug-resistant human immunodeficiency virus type 1 strains with unique patterns of pol gene mutations. J Infect Dis 1994, 169:722-729.

4. Shirasaka T, Yarchoan R, O'Brien MC, et al. Changes in drug sensitivity of human immunodeficiency virus type 1 during therapy with azidothymidine, dideoxycytidine, and dideoxyinosine: an in vitro comparative study. Proc Natl Acad Sci USA 1993, 90:562-566.

5. Shirasaka T, Kavlick MF, Ueno T, et al. Emergence of human immunodeficiency virus type 1 variants with resistance to multiple dideoxynucleosides in patients receiving therapy with dideoxynucleosides. Proc Natl Acad Sci USA 1995, 92: 2398-2402.

6. Schmit J-C, Cogniaux J, Hermans $\mathrm{P}$, et al. Multiple drug resistance to nucleoside analogues and nonnucleoside reverse transcriptase inhibitors in an efficiently replicating human immunodeficiency virus type 1 patient strain. J Infect Dis 1996, 174:962-968.

7. Schmit J-C, Van Laethem K, Ruiz L, et al. Multiple dideoxynucleoside analogue-resistant (MddNR) HIV-1 strains isolated from patients from different European countries. AIDS 1998, 12:2007-2015.

8. Van Laethem K, Witvrouw M, Balzarini J, et al. Patient HIV-1 strains carrying the multiple nucleoside resistance mutations are cross-resistant to abacavir. AIDS 2000, 14:469-471.

9. Winters M.A, Coolley KL, Girard YA, et al. A 6-basepair insert in the reverse transcriptase gene of human immunodeficiency virus type 1 confers resistance to multiple nucleoside inhibitors. J Clin Invest 1998, 102:1769-1775.

10. de Jong JJ, Goudsmit J, Lukashov VV, et al. Insertion of two amino acids combined with changes in reverse transcriptase containing tyrosine-215 of HIV-1 resistant to multiple nucleoside analogs. AIDS 1999, 13:75-80.

11. Larder BA, Bloor $\mathrm{S}$, Kemp $\mathrm{SD}$, et al. A family of insertion mutations between codons 67 and 70 of human immunodeficiency virus type 1 reverse transcriptase confer multinucleoside analog resistance. Antimicrob Agents Chemother 1999, 43:1961-1967.

12. Saag MS, Emini EA, Laskin OL, et al. A short-term clinical evaluation of L-697,661, a non- nucleoside inhibitor of HIV-1 reverse transcriptase. N Engl J Med 1993, 329:1065-1072.

13. Richman DD, Havlir D, Corbeil J, et al. Nevirapine resistance mutations of human immunodeficiency virus type 1 selected during therapy. J Virol 1994, 68:1660-1666.

14. Vandamme A-M, Debyser Z, Pauwels R, et al. Characterization of HIV-1 strains isolated from patients treated with TIBO R82913. AIDS Res Hum Retroviruses 1994, 10:39-46.

15. Balzarini J. Suppression of resistance to drugs targeted to human immunodeficiency virus reverse transcriptase by combination therapy. Biochem Pharm 1999, 58:1-27.

16. Balzarini J, Baba M, De Clercq E. Differential activities of 1-[(2hydroxyethoxy)methyl]-6-(phenylthio)thymine derivatives against different human immunodeficiency virus type 1 mutant strains. Antimicrob Agents Chemother 1995, 39:998-1002.

17. Balzarini J, Brouwer WG, Dao DC, Osika EM, De Clercq E. Identification of novel thiocarboxanilide derivatives that suppress a variety of drug-resistant mutant human immunodefi- 
ciency virus type 1 strains at a potency similar to that for wildtype virus. Antimicrob Agents Chemother 1996, 40:1454-1466.

18. Romero DL, Olmsted RA, Poel TJ, et al. Targeting delavirdine/ atevirdine resistant HIV-1: identification of (alkylamino)piperidine-containing bis(heteroaryl)piperazines as broad spectrum HIV-1 reverse transcriptase inhibitors. J Med Chem 1996, 39:3769-3789.

19. Buckheit RW, Snow MJ, Fliakas-Boltz V, et al. Highly potent oxathiin carboxanilide derivatives with efficacy against nonnucleoside reverse transciptase inhibitor-resistant human immunodeficiency virus isolates. Antimicrob Agents Chemother 1997, 41:831-837.

20. Balzarini J, Karlsson A, Meichsner C, et al. Resistance pattern of human immunodeficiency virus type 1 reverse transcriptase to quinoxaline S-2720. J Virol 1994, 68:7986-7992.

21. Kleim J-P, Bender R, Kirsch R, Meichsner C, Paessens A, Riess G. Mutational analysis of residue 190 of human immunodeficiency virus type 1 reverse transcriptase. Virology 1994, 200:696-701.

22. Kleim J-P, Bender R, Kirsch R, et al. Preclinical evaluation of HBY 097, a new nonnucleoside reverse transcriptase inhibitor of human immunodeficiency virus type 1 replication. Antimicrob Agents Chemother 1995, 39:2253-2257.

23. Kleim J-P, Winkler I, Rösner $M$, et al. In vitro selection for different mutational patterns in the HIV-1 reverse transcriptase using high and low selective pressure of the nonnucleoside reverse transcriptase inhibitor HBY 097. Virology 1997, 231:112-118.

24. Balzarini J, Pelemans H, Riess G, et al. Zidovudine-resistant human immunodeficiency virus type 1 strains subcultured in the presence of both lamivudine and quinoxaline HBY 097 retain marked sensitivity to HBY 097 but not to lamivudine. I Infect Dis 1997, 176:1392-1397.

25. Larder BA, Draby G, Richman DD. HIV with reduced sensitivity to zidovudine (ZDV) isolated during prolonged therapy. Science 1989, 243:1731-1734

26. Gu Z, Gao Q, Li X, Parniak MA, Wainberg MA. Novel mutation in the human immunodeficiency virus type 1 reverse transcriptase gene that encodes cross-resistance to $2^{\prime}, \mathbf{3}^{\prime}$-dideoxyinosine and 2', 3'-dideoxycytidine. J Virol 1992, 66:7128-7135.

27. Vandamme A-M, Witvrouw M, Pannecouque $C$, et al. Evaluating clinical isolates for their phenotypic and genotypic resistance against anti-HIV drugs. In: Methods in Molecular Medicine: Antiviral Methods and Protocols. Edited by Kinchington $\mathrm{D}$ Schinazi, RF. Totowa, NJ: The Humana Press; 1999:223-258:

28. Jonckheere H, Bebenek K, Kunkel TA, De Clercq E, Anné J. Fidelity analysis of HIV-1 reverse transcriptase mutants with an altered amino acid sequence at residues Leu74, Glu89, Tyr115, Tyr183 and Met184. Eur J Biochem 2000, 267:2658-2665.

29. Larder BA, Kemp SD, Harrigan PR. Potential mechanism for sustained antiretroviral efficacy of AZT-3TC combination therapy. Science 1995, 269:696-699.

30. Hsiou Y, Das K, Ding J, et al. Structures of Tyr188Leu mutant and wild-type HIV-1 reverse transcriptase complexed with the non-nucleoside inhibitor HBY 097: inhibitor flexibility is a useful design feature for reducing drug resistance. $/ \mathrm{Mol} \mathrm{BiO} /$ 1998, 284:313-323.

31. Kleim J-P, Rösner $M$, Winkler I, et al. Selective pressure of a quinoxaline nonnucleoside inhibitor of human immunodeficiency virus type 1 (HIV-1) reverse transcriptase (RT) on HIV-1 replication results in the emergence of nucleoside RT-inhibitorspecific (RT Leu-74 $\longrightarrow$ Val or Ile and Val-75 $\longrightarrow$ Leu or Ile) HIV-1 mutants. Proc Natl Acad Sci USA 1996, 93:34-38.

32. Boyer $\mathrm{PL}, \mathrm{Gao} \mathrm{H}-\mathrm{Q}$, Hughes $\mathrm{SH}$. A mutation at position 190 of human immunodeficiency virus type 1 reverse transcriptase interacts with mutations at positions 74 and 75 via the template primer. Antimicrob Agents and Chemother 1998, 42:447-452.

33. Balzarini J, Pelemans $H$, Esnouf $R$, De Clercq E. A novel mutation (F227L) arises in the reverse transcriptase of human immunodeficiency virus type 1 on dose-escalating treatment of HIV type 1-infected cell cultures with the nonnucleoside reverse transcriptase inhibitor thiocarboxanilide UC-781. AIDS Res Hum Retroviruses 1998, 14:255-260.

34. Huang H, Chopra R, Verdine GL, Harrison SC. Structure of a covalently trapped catalytic complex of HIV-1 reverse transcriptase: implications for drug resistance. Science 1998, 282: $1669-1675$

35. St. Clair MH, Martin JL, Tudor-Williams G, et al. Resistance to ddI and sensitivity to AZT induced by a mutation in HIV-1 reverse transcriptase. Science 1991, 253:1557-1559.

36. Brun-Vézinet $F$, Boucher $C$, Loveday $C$, et al. HIV-1 viral load, phenotype, and resistance in a subset of drug-naive participants from the Delta trial. The Lancet 1997, 350:983-990.

37. Larder BA, Kemp SD, Harrigan PR. Potential mechanism for sustained antiretroviral efficacy of AZT-3TC combination therapy. Science 1995, 269:696-699.

38. Calvez V, Delaugerre C, Rohban R, et al. Resistance profile and cross-resistance of HIV-1 among 102 patients failing nonnucleoside reverse transcriptase inhibitor-containing regimen. Fourth International Workshop on Drug Resistance and Treatment Strategies. Sitges, Spain, 12-16 June 2000 [Abstract 122].

39. Kemp S, Shi C, Bloor S, Harrigan P, Mellors J, Larder B. A novel polymorphism at codon 333 of human immunodeficiency virus type 1 reverse transcriptase can facilitate dual resistance to zidovudine and $\mathbf{1 - 2} \mathbf{1}^{\prime} \mathbf{3}^{\prime}$-dideoxy-3'-thiacytidine. J Virol 1998, 72:5093-5098.

40. Hertogs $\mathrm{K}$, Bloor $\mathrm{S}$, De Vroey $\mathrm{V}$, et al. A novel human immunodeficiency virus type 1 reverse transcriptase mutational pattern confers phenotypic lamivudine resistance in the absence of mutation 184V. Antimicrob Agents Chemother 2000, 44: 568-573.

41. Staszewski S, Hill AM, Bartlett J, et al. Reductions in HIV-1 disease progression for zidovudine/lamivudine relative to control treatments: a meta-analysis of controlled trials. AIDS 1997 11:477-483.

42. Masquelier B, Descamps D, Carriere I, et al. Zidovudine resensitization and dual HIV-1 resistance to zidovudine and lamivudine in the delta lamivudine roll-over study. Antiviral Ther 1999, 4:69-77. 